\title{
The Embodied Nature of Autistic Learning: Implications for Physical Education
}

Authors' contribution:

A) conception and design of the study

B) acquisition of data

C) analysis and interpretation of data

D) manuscript preparation

E) obtaining funding
Jing $\mathrm{He}^{1 \text { A-E }}$, Ejgil Jespersen ${ }^{2}$ A-E

${ }^{1}$ East China Normal University, China

${ }^{2}$ University of Southern Denmark, Denmark

ABSTRACT

Autism spectrum disorder (ASD) and learning difficulties are difficult to separate in clinic manifestations and diagnoses. By taking learning as being-in-the-world, this article considers the embodied nature of autistic learning and urges its importance for understanding the phenomenological core of ASD. We begin by arguing that three mainstream contemporary ASD theories are inherently limited in offering an adequate account of autistic learning due to the disembodied ontology inscribed within them. Then, we provide an understanding of learning guided by the subjective dynamics of experience. Instead of having a disembodied and individualistic point of view, we suggest that autistic learning has an embodied nature. The "inappropriate" or "abnormal" affections and behaviors in the autistic experience of learning may actually be inherently meaningful for individuals with ASD. They strive to make sense of some basic disturbances and re-establish some form of coherence with the world, though this may only be possible in the form of delusions or autistic withdrawals. Finally, we explore the relationship between autistic learning and physical education and suggest in particular how spontaneous imitation can boost the development of children with ASD. We conclude that the application of implicit learning strategies in playful settings and the reduction of explicit strategies based upon intellectual reasoning rather than bodily reciprocity should be encouraged in the process of autistic learning.

\section{Introduction}

The most notable deficits in Autism Spectrum Disorder (ASD) are social communication, social interaction, and restricted, repetitive patterns of behavior, interests, or activities. In addition, the cooccurrence of specific learning difficulties is also important in ASD in terms of problems in acquiring academic skills markedly below age level and manifested in the early school years (American Psychiatric Association, 2013). Most individuals with ASD have various learning difficulties. Individuals with highfunctioning ASD who possess average or above-average intelligence demonstrate different degrees of impaired shared attention, restricted interests, preference for detail, context-insensitivity, stereotypic thought 
processes, etc., in learning. Moreover, the severity of learning difficulties increases particularly in individuals with low-functioning ASD who have below-average intelligence.

Therefore, it is difficult to separate ASD and learning difficulties in clinic manifestations and diagnoses, and we may call the particular learning experience related to various learning difficulties of individuals with ASD "autistic learning". However, we should recognize the limitation of most understandings of ASD that focus exclusively on social deficits, given the array of other symptoms of learning difficulties in ASD that go beyond such problems. An integrative explanation, which is able to pull together social and non-social aspects of autistic learning, seems still farther off. Pushing one-step further, we may want to ask whether these divergent clinical manifestations of autistic learning might reflect one underlying common denominator (Stanghellini \& Ballerini, 2004). To answer this question, it is necessary to delve down into the nature of autistic learning.

By taking learning as being-in-the-world, this article considers the embodied nature of autistic learning and urges its importance for understanding the phenomenological core of ASD. We shall start with arguing that three mainstream contemporary ASD theories (theory of mind, weak central coherence theory, and interactive theory) are inherently limited in offering an adequate account of autistic learning because a disembodied or isolated ontology and alienated epistemology is implicitly inscribed within them. We thus question the more or less disembodied nature of autistic learning implied by the current understanding of ASD.

Then, informed both by empirical research and by works of phenomenological tradition, we provide an understanding of learning as being-in-the-world guided fundamentally by the subjective dynamics of our experience. Accordingly, instead of having a disembodied and individualistic point of view, we suggest that there is an embodied nature of autistic learning inspired by an idea of "autistic embodiment" put forward by De Jaegher (2013). The "inappropriate" or "abnormal" affections and behaviors in the autistic experience of learning may actually be inherently meaningful for individuals with ASD. They strive to make sense of some basic disturbances and re-establish some form of coherence with the world, though this may only be possible in the form of delusion or autistic withdrawals (Fuchs, 2010, p. 548). Finally, we explore the connectedness of autistic learning with physical education and suggest how imitation can boost the development of children with ASD (Nadel, 2014).

\section{ASD: Beyond three main theories}

A triad of impairments-social, communicative, and cognitive impairment-characterizes individuals with ASD. The more established explanatory theories addressing these aspects are theory of mind (ToM), weak central coherence theory (WCC), and interaction theory (IT). In this section, we are going to indicate how these theories constrain their explanatory power for autistic learning because of their problematic ontology.

Theory of Mind (ToM) is the most widely discussed approach used to explain the social aspects of ASD. It deals with our capacity for attributing mental states (beliefs, desires, and intentions) to the self and others in order to understand and predict behavior. Two distinct camps characterize this cognitive and modular approach of social interaction: the theory-theory and the simulation-theory. Variations have been taken in whole or in part by major research studies of cognitive science, developmental psychology, and pathology (e.g., Baron-Cohen et al., 1985; Frith, 1989; Goldman, 2006). For our purposes here, we shall only focus on the problematic theory-theory explanation of ASD. The theory-theory version of ToM contends that we understand others by implicit or explicit inferences of folk-psychological theory dealing with how mental states inform the behavior of others (Carruthers, 1996). Early experience, having some innate basis, develops automatically according to this theory. An instrument for theory testing measures the ability of four-year-old children to pass a false-belief test. Since individuals with ASD fail to pass the false-belief tests, theorytheorists argue that they lack the theory of mind and are unable to recognize their own and others' mental states. 
In recent years, criticism has been raised by phenomenological psychiatrists and philosophers (Fuchs, 2010; Zahavi \& Parnas, 2003; Gallagher, 2004, 2005). They argue that the ToM explanation of ASD focuses too much on the deficits of high-level inferential capacities in social interaction. Ironically, while 15 to 60 percent of individuals with ASD do pass the false-belief test, some individuals with disabilities other than ASD are not able to pass the test successfully (Gallagher, 2004, p. 204; Reed \& Paterson, 1990).

The underlying problematic assumption, however, is philosophical: there is a radical gap between the inner inferred mind and outer perceived behavior-other's minds are internal and hidden, and access to them consists of the external perceptible behavior. Based on this disembodied ontology (De Jaegher, 2013; Gipps, 2004) and alienated epistemology, ToM first fails to recognize that all experience, including autistic learning, should be sketched out in embodied and socially-contextualized situations. Second, ToM shows little concern for the experience of individuals with ASD, but underlines their deficit from the third-person, observational stance. Third, ToM is methodologically individualism. Even in the investigation of the social impairment of ASD, the dynamics of interaction do not play an explanatory role (De Jaegher, 2013).

Weak central coherence theory (WCC) intends to supplement the ToM explanation of the non-social aspect of ASD (Frith, 1989; Happé, 1995). This theory claims that individuals with ASD prefer local perception (Happé, 1996) and have deficits in contextual, global processing because of a lack of drive for central coherence (Gestalt Perception). This problem can give rise to both positive and negative effects in autistic learning. For example, individuals with ASD may have remarkable achievement in subjects like mathematics, yet have troubles in language learning; they may have unique talents for remembering a word string or unrelated items, and have an unusual weakness in understanding the contextual meaning of sentences (Happé, 1995; Gallagher, 2004). It seems that the explanation of WCC can contribute to explaining the non-social aspect of autistic learning, such as a restricted range of interests and a preference for detailed information.

However, a consensus has not yet been reached on the validity of WCC. Contrary to WCC, some recent studies indicate that global processing among individuals with ASD is actually intact. Thus, "The notions of local bias and global impairment that are part of WCC may need to be reexamined" (Mottron et al., 2003). There is also criticism concerning the range of the context that remains ambiguous in WCC. Systems and other matters that Frith and Happé automatically assumed to be universal have an essential social element.

Besides these controversial empirical results and terminology confusion, WCC also falls into the modern trap of objectivism and individualism. Accordingly, disembodiment and alienation are, in line with ToM, the founding principles, and thus fail to provide a coherent and convincing account of autistic learning.

A group of phenomenological psychiatrists and philosophers (Hobson, 1993; Zahavi \& Parnas, 2003; Gallagher, 2004; De Jaegher et al., 2010) have developed Interaction Theory (IT), which is the most promising approach of the three, as we see it. Rejecting the disembodied ontology and alienated epistemology of ToM and WCC, IT regards interaction as a practice "parasitizing on engaged, embodied, interactive dimensions of existence" (Gipps, 2004, p. 196), and suggests that ASD should rather be conceived as a problem of primary inter-subjectivity, which can disrupt secondary inter-subjectivity and contribute to problems with social cognition (Gallagher, 2004, p. 210). The phenomenological account of IT includes neurological, developmental, and cognitive analyses of ASD and makes the various experiences of autistic learning understandable in an intelligible way.

This theory, however, is not without problems. First, the form of embodiment of IT is contingent, rather than intrinsic in all human experiences. Therefore, fluent interaction depends on the healthy lived body, and ASD is intelligible in terms of the disembodied existence or disturbance of embodiment. The disturbances of selfness, of inter-subjectivity, deprive the ground of the lived body and its embodied spirit (Fuchs, 2010; Stanghellini \& Ballerini, 2004). Second, IT criticizes methodological individualism, which ToM is based upon. On the other hand, the theory itself seems somehow to over-emphasize "individuals" with ASD without placing them in an extended physical and social context, such as the personal experience 
or social structure. Our third contention deals with the interpersonal dimension of interaction in IT, which is relatively small-scale and trivial and pays little attention to the social-wide dimension of social cognition.

In summary, based upon a disembodied ontology and individualistic methodology, these three mainstream theories stress the causal explanation of the failure of sociability and make the subjective aspect of ASD itself into an object to be described rather than a medium allowing something to manifest itself. From these perspectives, "the need for an explanation of how we developmentally overcome this potentially insuperable epistemological hurdle would be all too patent" (Gipps, 2004, p. 196). However, this puzzle, or the mystery of autistic learning, disappears when we reject the disembodied ontology and turn back to the fundamentally embodied nature of autistic learning.

Before doing that, we offer an overview of the three main theories of ASD:

Table 1. An overview of the three main theories of ASD

\begin{tabular}{llll}
\hline & ToM & WCC & IT \\
\hline $\begin{array}{l}\text { Role of the body } \\
\text { The aspects of } \text { ASD } \\
\text { focused on }\end{array}$ & Social & Not important & Strong and weak \\
$\begin{array}{l}\text { Ontology } \\
\text { Methodology }\end{array}$ & Non-social & Social and non-social \\
\hline Limitation & Individualism & Disembodied & Conditional embodied \\
& $\begin{array}{l}\text { Neglect the sensory- } \\
\text { motor level }\end{array}$ & $\begin{array}{l}\text { Neglect the inter- } \\
\text { subjectivity level }\end{array}$ & $\begin{array}{l}\text { Contingent account of } \\
\text { embodiment }\end{array}$ \\
\hline
\end{tabular}

\section{How embodiment and learning are connected}

In this section, we provide an understanding of learning as being-in-the-world guided by the dynamics of our embodied experience. At the same time, we indicate how such a phenomenological approach could illuminate the experience of autistic learning through a set of concepts taken from Merleau-Ponty.

Modern western philosophy is the history of successive periods in the cultivation of the "mind", while the body became "discursively submerged" (O'Loughlin, 1995, p. 1) as the philosophical tradition developed. Intellectualists claim that learning is rooted in conceptual and innate knowledge, while empiricists contend that our experience is the sole origin of all knowledge. In the Cartesian tradition, they all regard mental phenomena as the objects of the disembodied mind. In Phenomenology of Perception, Merleau-Ponty launches his two-pronged attack on the empirical and intellectual approaches of learning for their split between what is inside the mind and what is outside in the objective world. Merleau-Ponty claims that what empiricism lacks is an internal connection between the object and the act it triggers, and what intellectualism lacks is the contingency of opportunities for thought.

"Consciousness is too poor in the first case and too rich in the second for any phenomenon to be able to solicit it" (Merleau-Ponty, 2012, p. 30).

Merleau-Ponty thus provides a "third approach" of learning-learning as being-in-the-world. He stresses that knowledge develops against the background of "this world" in our embodied experience 
(Merleau-Ponty, 2012, XXII). Therefore, to be learning in a "landscape" is to be acted out as an embodied process based on a particular way of being and the way the world appears to us. In strong contrast to intellectualists and empiricists, Merleau-Ponty emphasizes that human beings are neither disembodied intellects nor physical mechanisms, but lived bodies. The body simultaneously experiences in a world that responds with immediate meaning and contextual presence.

Merleau-Ponty's articulation of an "intentional arc" indicates the unity of the past, present, and future, the unity of the mind, body, and the world (Merleau-Ponty, 2012, p. 137). In this sense, experience is neither a collection of information about the past nor neutralized with respect to the process of learning; it conditions the learning process and gives it the lived bodily power of creating and repeating certain experiential forms. From this perspective, learning should be considered a less subjective activity, carving the subject's own path with his or her unique experience, in which the subject's past and present are constantly mediated thanks to the body itself.

Another important notion related to learning is getting a "maximal grip", which indicates the intimate connection between the body and the world in the experience of learning. The context calls for our bodies to get into equilibrium with the environment according to Merleau-Ponty (2012, pp. 315-316). In order to achieve the body-environment optimum, the body is inclined to refine its response to our sense of the context. Even in most cases, we do not need to know, nor can we express, what that optimum is. To get this flavor, Dreyfus invites us to consider an example of skill learning: playing tennis (Dreyfus, 2002, pp. 37879).

As a beginner, she tends to be aware of her own body in terms of being conscious of limb position, movement, and posture, and makes an effort to keep the racket perpendicular to the court, hit the ball squarely, etc. However, after becoming an expert player, she simply knows what to do, generally without any explicit awareness. The body functions in a tacit way. The learner tends to discriminate more and more refined contexts and to take more and more appropriate actions, whereby the process of learning enriches the intentional arc. In this sense, learning capacity is the body's tendency to acquire a maximal grip on the situation. We learn, or rather, our body takes over and learns for us.

Yet, how is it possible for the experience to serve as a foundation for present learning without any explicit awareness? Merleau-Ponty's idea of "ambiguity" is a good answer. Following Husserl, MerleauPonty makes an important distinction between subject-body and object-body. Subject-body is the body that pre-reflectively lives as an incarnated subject, while object-body is the physical body that we can perceive or others can perceive (Fuchs, 2010, p. 551). In our normal, healthy body experiences, these two dimensions of body are supporting each other.

Based on a set of tacit sensory-motor functions, the subject-body is highly anonymous in its habitual ways of coping with the world, and it operates best when the intentional object of perception is something other than the body. That is how our body is able to efface itself and aim for goals in the process of learning. It does not mean that the body is absent; rather, it functions as a foundation in a transparent way so that we can just focus on the intentional goal. However, we should not take it for granted all the time. The body suddenly appears as an object in consciousness when something goes wrong with it. The two dimensions of subject-body and object-body are thus disrupting harmony. In all of our experiences, our bodies are the main priority simply due to the fact of human beings' embodiment. Therefore, the body has an ambiguous experiential status: it is both a subject-body and an object-body. As Fuchs rightly points out, "an ongoing oscillation between these two bodily modes constitutes a fluid and hardly noticed foundation of all experiencing" (Fuchs, 2010, p. 551).

In summary, the interpretations of intentional arc, maximum grip, and ambiguity within MerleauPonty's philosophy allow us to understand learning as a fundamentally embodied experience. Normally, the healthy subject-body sets the stage of our experience of learning. However, as Merleau-Ponty (2012, p. 170) argues, it "'goes limp' in the disorder". Given the central role of the body in learning, a disorder of the body 
entails a change in the whole way of one's being-in-the-world, and, therefore, modifies the meaning and process of one's learning experience.

\section{Autistic learning as an autistic embodied experience}

Since embodiment and learning are intrinsically connected, the body partly determines how we learn. The learning experience is, moreover, that of a specific agent, not that of a passive receiver. That is, in the process of learning, we interact with the world and pick up what is relevant to us. However, an alternative way of being-in-the-world is coming to the fore in the sensorimotor, perceptual, affective style of autistic learning. The "morbid" or "abnormal" affections and actions of autistic learning may actually be inherently meaningful to individuals with ASD. In this sense, autistic learning as an autistic embodied experience is, in its essence, no different from non-autistic learning. This understanding is not just cognitive, but is also an experience on a lived body level.

\section{Sensory-motor system: Behavioral level}

It has been demonstrated that a variety of basic sensory-motor deficits exist in people with ASD. Sensory-motor system is especially important for motor learning, including sitting, walking, mouth-shaping, and writing. When disruption happens, motor development and learning is affected.

While sensory-motor differences are not considered centrally in ToM and WCC, they "feature prominently in many autobiographical accounts" (De Jaegher, 2013, p. 8). People with ASD may ignore other people talking to or touching them, but be hyposensitive or hypersensitive to particular events. For example, the tactile sense of a new tablecloth may hurt people with ASD. There is good evidence showing that sensory sensitivity has contributed to the problem of attention and attention shifting (Liss et al., 2006). Liss suggests that hyposensitivity and hypersensitivity are caused by the decreased ability to modulate attention. Attention is an important aspect of learning in general, but attention shifting seems to be slower in autistic learning. Gepner and Mestre (2002) propose that the world seems to move too fast for people with ASD, and they need to slow it down by exploring it in a particular way.

Restricted interests and repetitious movements are also characteristic of autistic learning. Restricted interests are very common in ASD (Spiker et al., 2012; De Jaegher, 2013). It seems that individuals with ASD have some intrinsic motivation toward learning some particular talents and skills, and learning them and other certain information can be interesting in its own right. Research shows that restricted interests are highly encouraging for learners with ASD. They encourage them to learn, guide them to some gist of the picture (Hung, 1978), and involve increasing social interactions with peers, since this is a way to deal with distress (Baker, 2000). On the other hand, repetitious movements in learning also serve to relax a student with ASD while acting as a coping mechanism against the anxiety of interacting with others. Bodfish et al. (2000) found that in comparing two groups of students with learning difficulties, one with and one without ASD, the group of students with ASD displayed increased severity and frequency of repetitious movements during the process-of-learning section. This may also explain why people with ASD usually ignore the gist or the totality of an event or object, but are at ease with their preference for irrelevant details and piecemeal processing.

Therefore, the disruption of the sensory-motor system not only limits the type of learning in which people with ASD can engage, but also reconfigures their whole way of learning. This disruption modifies their movements, interests, efforts, attention, and assessment of duration. Restricted interests, a preference for details, repetitive movements, and other sensory-motor particularities often disturb the learning progress and make it difficult both for the learner with ASD and his or her instructors. However, as De Jaegher argues, "this does not imply that they could not in themselves be relevant, salient or significant for the person with autism....dealing with them should also start from the meaning they have for the person with autism, not just from the question of whether they are appropriate" (De Jaegher, 2013, p. 8). 


\section{Inter-subjectivity: Social level}

Learning is a socially-embedded experience because of the social nature of human beings. It is no exaggeration to say that all of the processes of learning, whether in explicit or implicit learning, involve inter-subjectivity. Even in our earliest learning experience, the reactions of others shape our behavior so that we learn to control our bodily movement, express our needs, master our mother tongue, and understand others. In explicit learning, being involved in learning is like being in a relationship: we are always relating to others, interpreting texts, following teachers' instructions, talking with schoolmates, and coming back to ourselves. This socially dynamic structure, expressed in the relationship, precisely characterizes the learning experience. In other words, our interpersonal engagement depends upon learning.

However, people with ASD often seem "awkward" in the way they connect with others in the process of learning. Their lack of involvement in, and probably appreciation of, other's words or actions is "reflected in their tendency not to share or exchange experiences or thoughts with others, for example, in failing to show or to tell people things", which is an important part of the learning process (Hobson, 1990, p. 174). Hobson (1990) claims that people with ASD lack "the biological basis for coherent, affectively patterned experience and interpersonal relatedness, they are not only handicapped in arriving at an affectively centered 'core' self, but also partly or wholly deprived of the experience of being invested in, and having commonality with people" (p. 176). Therefore, people with ASD have serious difficulty in acquiring a concept of self and others.

However, we argue that we should distinguish the minimal self from the narrative self (Gallagher, 2005; Fuchs, 2010). From a phenomenological point of view, a tacit, pre-reflective self-awareness that is present in every experience without reflection characterizes the minimal self. Thus, every perception and action involves an implicit self-awareness which is "immediately, non-inferentially" given self-ownership (Fuchs, 2010, p. 549). In contrast, the narrative self is a more or less coherent self that is constituted by a number of capacities such as perspective-taking and self-other distinction.

The minimal self is not an abstract concept, but involves the dimension of embodiment and is unextended in time. Some studies demonstrate that people with ASD have at least a minimal self, and have more mastery of basic interaction in learning than expected. Children with ASD do remove lip rouge from their face when they see themselves in a mirror (Hobson, 1990). It does not follow that they have an elaborated concept of self; however, it does show that they have a basic sense of self and self-ownership. Furthermore, Dickerson et al. (2007) argue that people with ASD can temporarily engage in learning interaction. Dickson and his colleagues found that in the question-and-answer sections, children repeatedly tapped the presented answering cards. These responsive actions were systematically placed exactly at the points where it was appropriate for students to provide answers to the tutor's question, but before students had completed their answers. Instead of regarding these motor actions as irrelevant in interaction or symptomatic of an underlying pathology, Dickson and his colleagues suggest that the tapping displayed engagement; this communicative gesture in learning interactions served as a sign to indicate that the student was about to answer the question.

As De Jaegher $(2013,12)$ rightly points out, "While there is a general and rather vague idea that people with autism are 'awkward' in their interactions, until we investigate those interactions, we do not know what this means or entails....although further research is needed, the evidence points to various problems with interaction in autism, but also unexpected capabilities". The disorder of the body may reduce the scope and possibility of flexibility and coherence in interaction, but people with ASD still strive for coherent sense-making in the form of autistic withdrawals.

\section{Implicit learning ability: Intellectual level}

Learning takes place both in explicit and implicit forms. Explicit learning is when people acquire knowledge, understanding, and skills by conscious application in formal settings. Implicit learning is the learning that proceeds without apparent effort in informal settings and results in knowledge, understanding, 
and skills that improve performance even when it is difficult to verbalize (for discussion see Brown et al., 2010, p. 1790-91; Gallagher, 1992). While an individual's IQ is strongly related to explicit learning, implicit learning performance is not as correlated (Gebauer \& Machintosh, 2007, 2009; Kaufman et al., 2009; Reber et al., 1991).

Implicit learning is an important mechanism for communicative, social, and motor skill acquisitions (Winch, 2001; Gallagher, 1992). Therefore, the communication, interaction, and motor difficulties of ASD may be caused by a general deficit in implicit learning. Several studies have claimed that there are impairments in implicit learning for people with ASD. For example, students with ASD performed worse than normally developing students on an implicit learning procedure. However, recently, Brown et al. (2010) questioned the validity of these results and judgments. They argue that if the task of learning procedures encourages explicit learning with a highly correlated IQ, given that the group with ASD has a lower IQ, the autistic learning deficit would be expected and more likely attributable to the explicit learning process. The performance deficit observed so far by previous studies may actually arise by other particularly explicit, cognitive processes. Therefore, they compared groups with and without ASD on five implicit learning tasks: contextual cueing, serial reaction time, artificial grammar learning, and probabilistic classification learning tasks that used procedures expressly designed to minimize the employment of explicit strategies. In a surprise twist, their data suggest that implicit learning is actually intact in people with ASD. That is to say, people with ASD can learn implicitly. Furthermore, they propose that it is unlikely that implicit learning processes are directly responsible for impairments in communication, interaction, and motor skills. Their findings are in accordance with other recent reports of intact implicit learning ability in people with ASD, such as Barnes et al. (2008).

These latest findings suggest that learning capabilities in terms of implicit learning are not lost in ASD and, thus, they undermine the argument that intellectual deficits play a key role in autistic learning. This urges us not to consider autistic learning an intellectual-based, high-level, information-input process, but fundamentally an embodied autistic experience which brings together the sensory-motor, social, experiential, and affective aspect of autism in a coherent dynamic process. Once we take this perspective, we can start to make sense of the world of autism and of autistic particularities of learning.

\section{A physical education-oriented approach for autistic learning}

Informed both by empirical research and by works of phenomenological tradition, we defined the embodied nature of autistic learning. By taking learning fundamentally as a dynamic experience, the particularities of autistic learning can be seen as alternative ways of being-in-the-world. The disorder of one's body may lead to a change in the whole way of being-in-the-world. The seemly abnormal and irrelevant autistic behaviors, affections, and aspects of learning are actually inherently meaningful to individuals with ASD attuned to their embodied and embedded context.

Based upon this embodied account of autistic learning, we shall, finally, sketch a physical educationbased approach for autistic learning. Physical education is an approach to the body which influences teaching, learning, and affection in bodily-based programs, especially when focused on individual interests, strengths, and potentials (Connolly, 2013, p. 236). It is based on the premise that the experiencing body is the anchor of our being and meaning-making. The substance of this approach is contextualizing, refining, and maximizing physical patterns and strengths to build healthy adaptive behavior and focus on individual interests, strengths, and potentials.

A good example is the embodied and embedded curriculum developed by Connolly (2013). As a physical educator who has worked with ASD individuals for over 30 years, Connolly considers the habits of subjects, which are consistent and form the core of the embedded curriculum. However, the content and processes of the curriculum have developed over time and are adaptable to each individual's needs. In order to achieve this, movement profiling plays an important role in physical education, allowing a teacher to observe a mover over time and across contexts using the features and components of each theme to develop a 
"movement fingerprint", such that not only dominant patterns become apparent, but also missing features become apparent (Connolly, 2008).

However, one important phenomenon of learning seems to be missing in Connolly's PE curriculum, namely imitation. That may be due to a widespread belief in ASD research that people with ASD do not imitate and in fact are not capable of it at all (Nadel, 2014, p. 92). Even a renowned phenomenologist like Fuchs considers autism to be a disorder of primary or embodied inter-subjectivity and refers to findings that people with autism do not readily imitate the actions of others (Fuchs, 2010, pp. 553-554). A mirror neuron dysfunction may be a cause of this alleged deficit.

More specifically, when dealing with curriculum, one may be inclined to focus more on teaching by instruction rather than the pupils' spontaneous learning processes. Teachers think that these children must be instructed to imitate, which easily leads to the proposal of movements and actions that are not meaningful to them. Therefore, when asking children to "do what I do", the requested movements are usually not successful, i.e., the students cannot imitate. But even if they may not be able to imitate on demand, the capacity for imitation can express itself in ways other than instruction.

When recalling the above-mentioned studies showing that implicit learning is actually intact among people with ASD, it is fully understandable that spontaneous imitation is in fact working well in most cases. Indeed, some studies have shown that there are many possible benefits if a child with ASD imitates the actions of another and recognizes being imitated (Nadel, 2014, p. 104; Jensen, 2014, pp. 47-48).

Inspired by Connolly's practice and based upon what we discussed above, we propose that, first, all physical interventions should be person-centered, bodily-based, and bodily dignified. Many behaviors associated with ASD can be seen as embodied solutions to existential, neurological, sensory, or motor traumas or crises rather than as outbursts of disembodiment (Connolly, 2014). The improvement of sensorymotor performance may contribute to better social interactions and other aspects of autistic learning such as repetitious movement, oversensitivity to stimuli, and restricted interests (Gallagher, 2010).

Second, learning disabilities are often pointed out in autistic learning since more than two-thirds of individuals with ASD are low-functioning. However, recent research shows that they have preserved implicit learning capabilities including a capacity for spontaneous imitation, which is so important in physical education. In the process of learning, we should encourage the application of implicit learning strategies in playful settings and reduce the overuse of explicit strategies based upon intellectual reasoning rather than bodily reciprocity. If implicit learning processes are utilized in synchronization with physical education, the results can potentially enhance the quality of autistic learning by raising awareness of personal strengths, increasing trust in personal ability (i.e., empowerment), helping individuals learn to engage in relationships, and increasing self-satisfaction through success (Zager, 2013).

Third, as present works indicate, a flexible interaction with others and the world can aid in the flexibility and creativity of behavior and thinking in general (Hobson, 2010; De Jaegher, 2013). As individuals with ASD learn to direct their energy into physical strength and potential, flexible interaction and improved learning may occur. Physical training is fostered through structured schedules and goals. By helping students learn new skills and concepts, a state of trust and comfort between the interaction of students, teachers, and the learning environment is created. Also, the motivation of proceeding with learning activities is increased. This has been shown empirically to be true, especially for young children with very limited repertories (Zager, 2013).

In short, the embodied nature of autistic learning enables us to understand the particularities of those with ADS in a coherent and comprehensive way from a first-person perspective of being and draws attention away from their "abnormal" behavior. In order to deal with these particularities, we should start from the different but embodied way that they relate with the world and others, rather than questioning their appropriateness and validity. 


\section{Acknowledgements}

This paper is supported by the MOE (Ministry of Education in China) Project of Humanities and Social Science (Grant No.13YJC720015) and Centre of Adapted Physical Activity Participation Studies, University of Southern Denmark. Thanks to Shaun Gallagher for helpful comments.

\section{REFERENCES}

American Psychiatric Association (Eds.). Diagnostic and Statistical Manual of Mental Disorders, Fifth Edition. Retrieved March 11, 2015, from http://dx.doi.org/10.1176/appi.books.9780890425596.

Baker, M.J. (2000). Incorporating the thematic ritualistic behaviors of children with autism into games: increasing social play interactions with siblings. J. Posit. Behav. Intervent., 2, 66-84.

Barnes, K.A., Howard, J.H.Jr., Howard, D.V., Gilotty, L., Kenworthy, L., Gaillard, W.D., Vaidya, C.J. (2008). Intact implicit learning of spatial context and complex sequences in childhood autism spectrum disorder. Neuropsychology, 22(5), 563-570.

Baron-Cohen, S., Leslie, A.M. \& Frith, U. (1985). Does the autistic child have a theory of mind? Cognition, 21, 37-46.

Bodfish, J.W. (2007). Stereotypy, Self-Injury, and Related Abnormal Repetitive Behaviors. In Jacobson, J.W., Mulick, J.A. \& Rojahn, J. (Eds.), Handbook of Intellectual and Developmental Disabilities (pp. 481-506). Berlin: Springer Science + Business Media.

Brown, J., Aczel, B., Jiménez, L., Kaufman, S.B. \& Grant, K.P. (2010). Intact implicit learning in autism spectrum conditions. The Quarterly Journal of Experimental Psychology, 63(9), 1789-1812. DOI:10.1080/17470210903536910.

Carruthers, P. (1996). Simulation and self-knowledge: A defense of theory-theory. In Carruthers, P. \& Smith, P.K. (Eds.), Theories of Theories of Mind (pp. 22-38). Cambridge: Cambridge University Press.

Connolly, M. (2008). The remarkable logic of autism: developing and describing an embedded curriculum based in semiotic phenomenology. Sport, Ethics and Philosophy, 2(2), 234-256.

De Jaegher, H. (2013). Embodiment and sense-making in autism. Frontiers in Integrative Neuroscience, 7, Article 15.

De Jaegher, H., Di Paulo, E.A. \& Gallagher, S. (2010). Can social interaction constitute social cognition? Trends in Cognitive Science, 14, 441-447.

Dickerson, P., Stribling, P. \& Rae, J. (2007). Tapping into interaction: how children with autistic spectrum disorders design and place tapping in relation to activities in progress. Gesture, 7, 271-303.

Dreyfus, H.L. (2002). Intelligence without representation - Merleau-Ponty's critique of mental representation. Phenomenology and Cognitive Science, 1, 367-383.

Frith, U. (1989). Autism: Explaining the Enigma. Oxford: Blackwell.

Fuchs, T. (2010). Phenomenology and Psychopathology. In Gallagher, S., \& Schmiching, D. (Eds.), Handbook of Phenomenology and Cognitive Science (pp. 547-573). Berlin: Springer Science + Business Media.

Gallagher, S. (1992). Hermeneutics and Education. Albany: State University of New York Press.

Gallagher, S. (2004). Understanding interpersonal problems in autism: interaction theory as an alternative to theory of mind. Philosophy, Psychiatry, \& Psychology, 11(3), 199-217.

Gallagher, S. (2005). How the Body Shapes the Mind. Oxford: Clarendon Press.

Gepner, B. \& Mestre, D. (2002). Rapid visual-motion integration deficit in autism. Trends in Cognitive Science, 6, 455.

Gipps, R.G.T. (2004). Autism and intersubjectivity: beyond cognitivism and the theory of mind. Philosophy, Psychiatry, \& Psychology, 11(3), 195-198.

Goldman, A.I. (2012). Theory of Mind. In Margolis, E., Samuels, R. \& Stich, S. (Eds.), The Oxford Handbook of Philosophy of Cognitive Science (pp. 402-424). Oxford: Oxford University Press.

Happé, F. (1995). Autism: An Introduction to Psychology. Cambridge: Harvard University Press.

Hobson, R.P. (1990). On the origins of self and the case of autism. Development and Psychopathology, 2, 163-181.

Hobson, R.P. (1993). Autism and the Development of Mind. Howe, Sussex: Erlbaum.

Hobson, R.P. (2010). Explaining autism: Ten reasons to focus on the developing self. Autism, 14(5), 391-407.

Hung, D. (1978). Using self-stimulation as reinforcement for autistic children. J. Autism Child Schizophr., 8, 355-366.

Jensen, K.S. (2014). Kropslig situeret lcering. Et casestudie af lcering i idrcetsundervisningen for elever med ASF på Taps skole /Bodily situated learning: a case study of learning in physical education for pupils with ASD at Taps Schooll. Aarhus: Department of Public Health, Aarhus University. 
Liss, M., Saulnier, C., Fein, D. \& Kinsbourne, M. (2006). Sensory and attention abnormalities in autism spectrum disorder. Autism, 10, 155-172.

Merleau-Ponty, M. (2012). Phenomenology of Perception. Oxon: Routledge.

Mottron, L., Burack, J., Iarocci, G., Belleville, S. \& Enns, J. (2003) Locally oriented perception with intact global processing among adolescents with high-functioning autism: evidence from multiple paradigms. Journal of Child Psychology and Psychiatry, 44(6), 904-913.

Nadel, J. (2014). How Imitation Boosts Development. Oxford: Oxford University Press.

O’Loughlin, M. (1996). Embodiment and Education: Exploring Creatural Existence. Berlin: Springer.

Reber, A.S., Walkenfeld, F.F. \& Hernstadt, R. (1991). Implicit and explicit learning: Individual differences and IQ. Journal of Experimental Psychology, 17(5), 888-896.

Reed, T. \& Paterson, C. (1990). A comparative study of autistic subjects' performance at two levels of visual and cognitive perspective taking. Journal of Autism and Developmental Disorders, 29, 555-68.

Spiker, M.A., Lin, C.E., Van Dyke, M. \& Wood, J.J. (2012). Restricted interests and anxiety in children with autism. Autism, 16, 306-320.

Stanghellini, G. \& Ballerini, G. (2004). Autism: Disembodied existence. Philosophy, Psychiatry, \& Psychology, 11(3), 260.

Winch, C. (2001). The Philosophy of Human Learning. London: Routledge.

Zager, D. (2013). Positive Psychology and Autism Spectrum Disorders. In Wehmeyer, M.L. (Ed.), The Oxford Handbook of Positive Psychology and Disability (pp. 494-505). Oxford: Oxford University Press.

Zahavi, D. \& Parnas, J. (2003). Conceptual problems in infantile autism research: why cognitive science needs phenomenology. Journal of Consciousness Studies, 10(9-10), 53-71.

\section{AUTHOR'S ADDRESS:}

Ejgil Jespersen

Institute of Sports Science and Clinical Biomechanics

University of Southern Denmark

Campusvej 55, DK-5230 Odense M, Denmark

E-mail: ejjespersen@health.sdu.dk 